\title{
CORRECTION
}

View Article Online

View Journal I View Issue

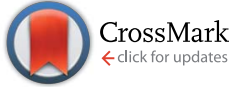

Cite this: RSC Adv., 2015, 5, 72590

DOI: $10.1039 / \mathrm{c} 5 \mathrm{ra90080h}$

www.rsc.org/advances

\section{Correction: Sensitive and selective determination of aqueous triclosan based on gold nanoparticles on polyoxometalate/reduced graphene oxide nanohybrid}

\author{
Mehmet Lütfi Yola, ${ }^{a}$ Necip Atar, ${ }^{\text {b }}$ Tanju Eren, ${ }^{b}$ Hassan Karimi-Maleh ${ }^{c}$ \\ and Shaobin Wang*d
}

Correction for 'Sensitive and selective determination of aqueous triclosan based on gold nanoparticles on polyoxometalate/reduced graphene oxide nanohybrid' by Mehmet Lütfi Yola et al., RSC Adv., 2015, 5, 65953-65962.

The authors regret that mistakes were made in the preparation of Fig. 6 and Table 1 in the original article. Several of the line colours presented in the legend for Fig. 6A do not correspond to the correct curves in the plot. The correct image for Fig. 6 is shown below.
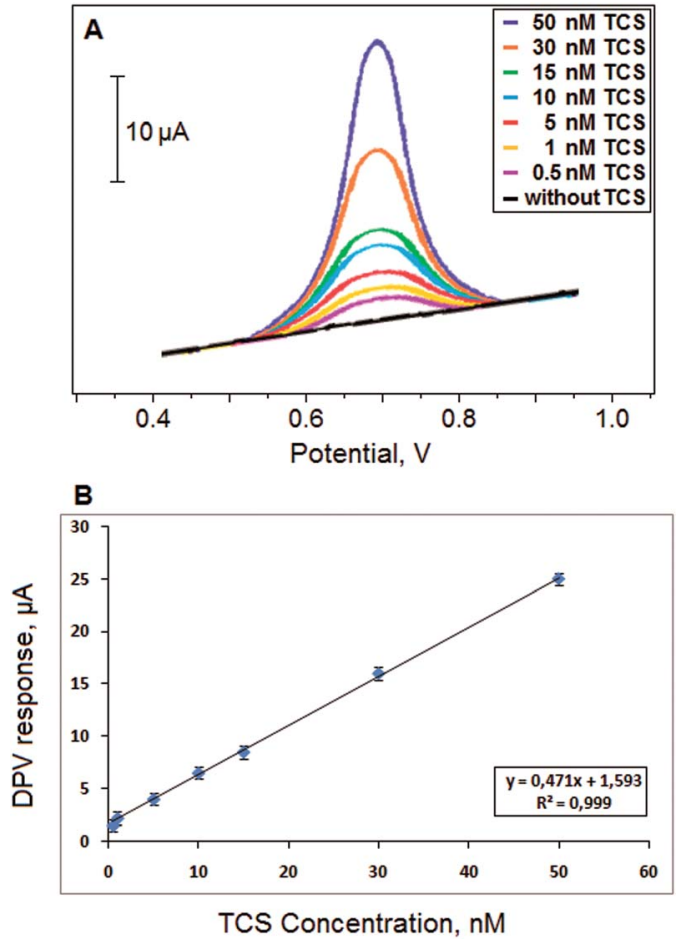

Fig. 6 DPV profiles of the electrochemical sensor at different TCS concentrations in phosphate solution $\mathrm{pH} 7.0$ from background without TCS to $50.0 \mathrm{nM}$ TCS (A), and linear calibration curve of TCS (B).

${ }^{a}$ Department of Metallurgical and Materials Engineering, Sinop University, Sinop, Turkey

${ }^{b}$ Department of Chemical Engineering, Pamukkale University, Denizli, Turkey.E-mail: necipatar@gmail.com

${ }^{c}$ Department of Chemistry, Graduate University of Advanced Technology, Kerman, Iran

${ }^{d}$ Department of Chemical Engineering, Curtin University, GPO Box U1987, Perth, WA 6845, Australia. E-mail: shaobin.wang@curtin.edu.au 
Additionally, two of the values presented in Table 1 in the original manuscript are incorrect. The "Recovery (\%)" value for the "Wastewater" sample with 9.0 nM added TCS should be $100.0 \pm 0.02$, rather than $99.8 \pm 0.6$. The "Found TCS (nM)" value for the "Lakewater" sample with $6.0 \mathrm{nM}$ added TCS should be $7.67 \pm 0.02$, rather than $9.67 \pm 0.02$. The corrected version of Table 1 is shown below.

Table 1 The TCS recoveries in wastewater and lakewater samples $(n=6)$

\begin{tabular}{|c|c|c|c|}
\hline Sample & Added TCS (nM) & Found TCS (nM) & Recovery (\%) \\
\hline \multirow[t]{3}{*}{ Wastewater } & - & $3.10 \pm 0.03$ & - \\
\hline & 3.0 & $6.03 \pm 0.02$ & $98.9 \pm 0.5$ \\
\hline & 9.0 & $12.1 \pm 0.02$ & $100.0 \pm 0.2$ \\
\hline \multirow[t]{2}{*}{ Lakewater } & - & $1.66 \pm 0.06$ & - \\
\hline & 3.0 & $4.65 \pm 0.04$ & $99.8 \pm 0.6$ \\
\hline
\end{tabular}

The Royal Society of Chemistry apologises for these errors and any consequent inconvenience to authors and readers. 